\title{
Hip pain- a symptom to be vigilant in hypercortisolism...
}

\author{
Gamage K K K ${ }^{1}$, Dematapitiya $C^{1}$, Pathmanathan $S^{1}$, Sumanatilleke M R ${ }^{1}$ \\ Diabetes and Endocrinology Unit. National Hospital of Sri Lanka
}

Correspondence email: kavingakg@gmail.com

D https://orcid.org/0000-0002-3943-7336

A 64-year-old female with background history of hypertension presented with proximal myopathy, pigmentation and easy bruising. She also complained of left sided hip pain which was worse with movement. There was no preceding history of fever. Examination revealed a BMI of $20.2 \mathrm{~kg} \mathrm{~m}^{-2}$, central obesity with thin extremities. There was round facies, facial plethora and thin skin. There were patches of ecchymoses and pigmented extremities with hyperpigmented nails (figure 1A, 1B). Blood pressure was 150/90mmHg. She had an antalgic gait. Examination of the hips revealed painful hip movements on left hip as well as right hip. Laboratory investigations were significant for

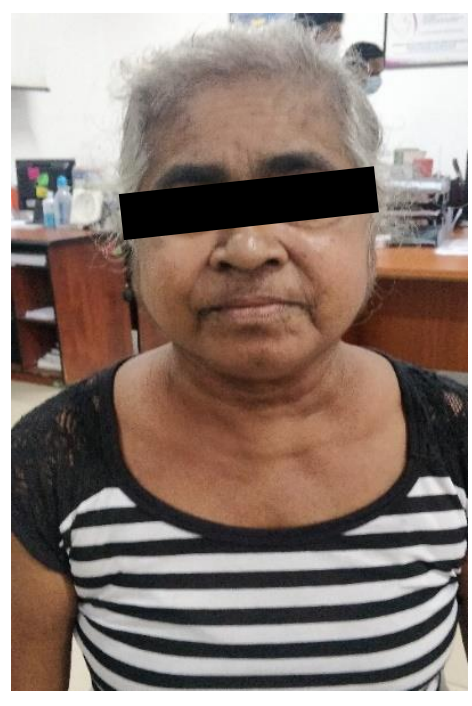

Figure 1: Patient's external appearance and pigmented extremities hypokalemia (serum Potassium $3.3 \mathrm{mmol} / \mathrm{L}$ ) and overnight dexamethasone test was not suppressed $(416 \mathrm{nmol} / \mathrm{L})$. X-ray hips showed left sided crescent sign (figure 2). Magnetic Resonance Imaging of bilateral hips were done after orthopedic opinion which showed bilateral T1 hypo intensity and T2 heterogeneous hyperintensity and double line sign at the femoral heads (figure 3). Further evaluation reveled an ACTH of $23.2 \mathrm{ng} / \mathrm{dL}$ suggestive of ACTH dependent Cushing. Inferior petrosal sinus sampling confirmed pituitary dependent ACTH hypersecretion (table 1), unfortunately lateralization was not possible. MRI pituitary revealed a left sided pituitary microadenoma (figure 4).

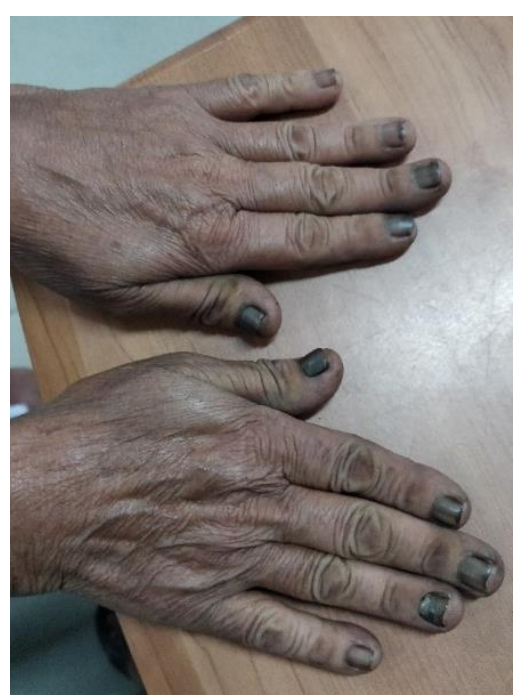

This is an open-access article distributed under the terms of the Creative Commons Attribution License, which permits unrestricted use, distribution, and reproduction in any medium, provided the original author and source are credited (CC BY 4.0) 


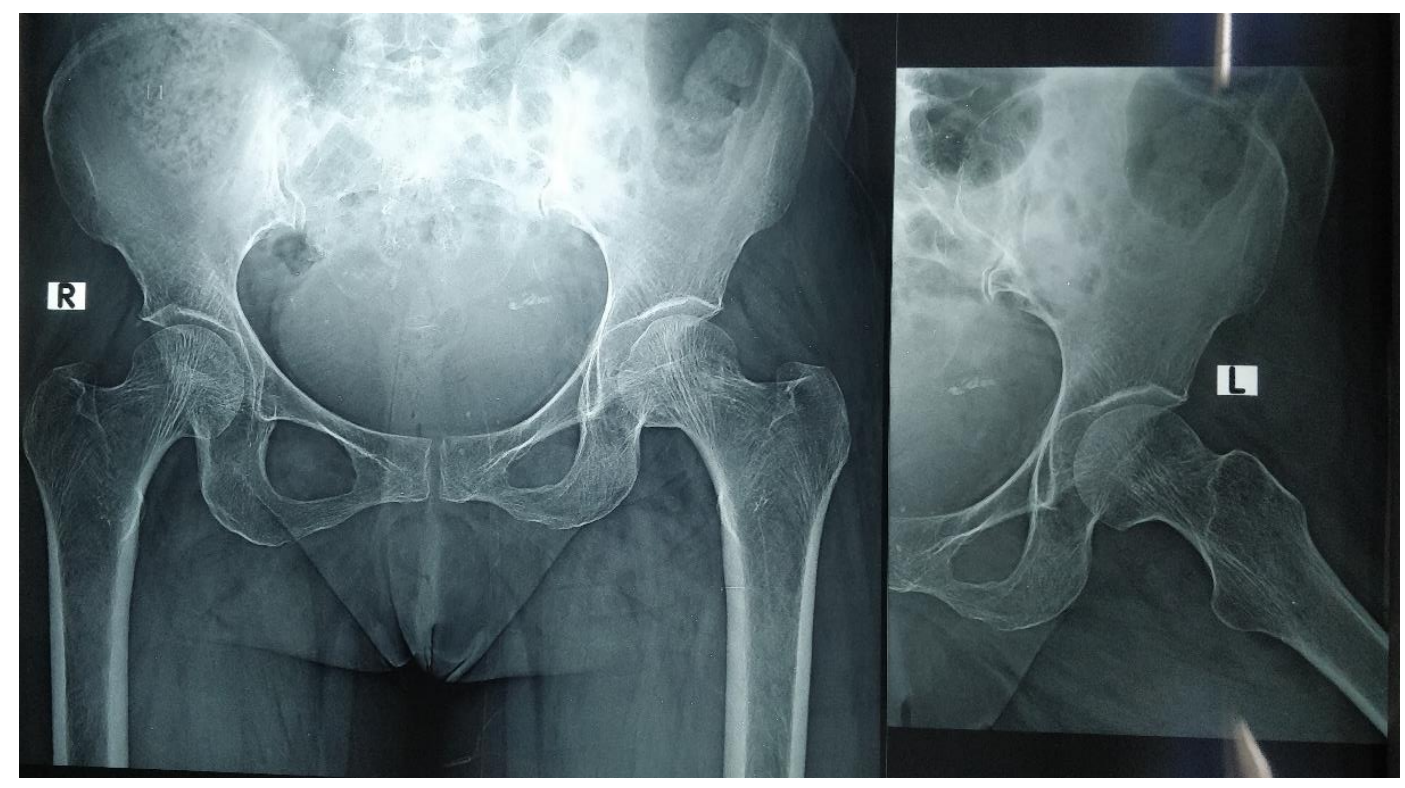

Figure 2: X-ray bilateral hip joints AP view

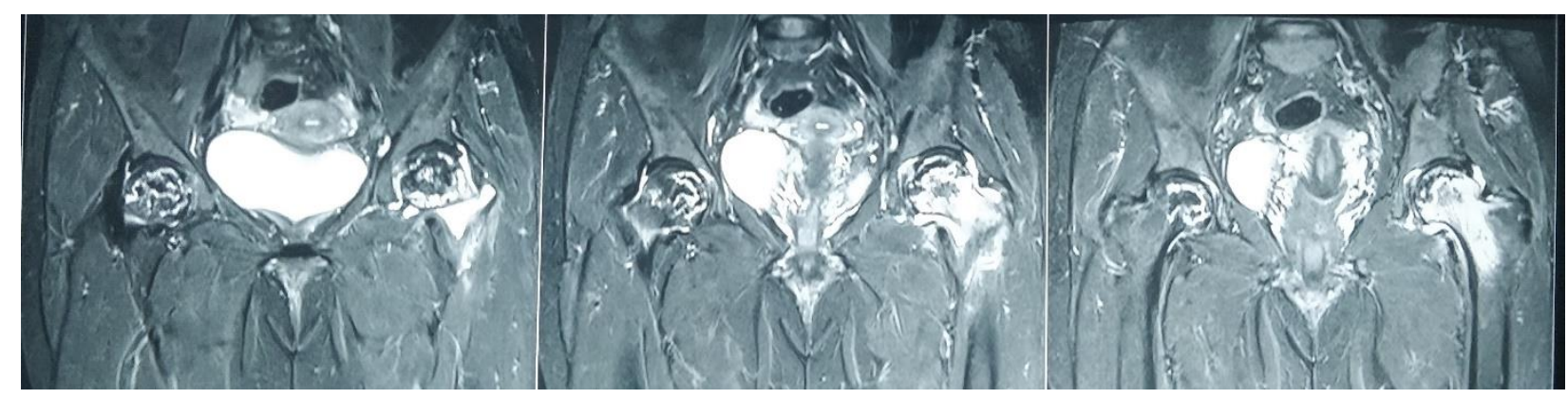

Figure 3: MRI imaging of bilateral hips

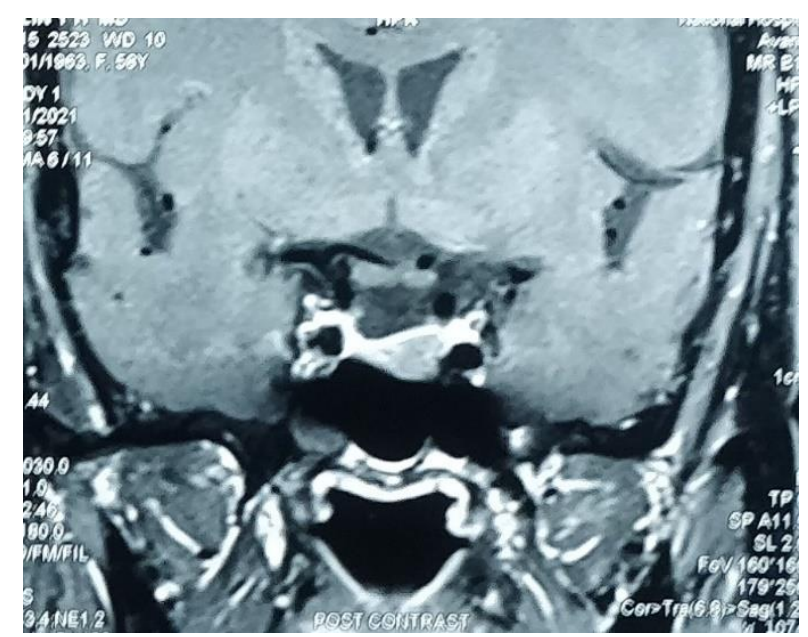

Figure 4: MRI pituitary post contrast imaging showing 10x 7x $8 \mathrm{~mm}$ lesion on the left side of the pituitary 
Table 1. Results of inferior petrosal sinus sampling

(Prolactin central to peripheral ratio: Right side 1.86, left side 1.44; Central to peripheral

ACTH ratio: Right side 2.74 , Left side 2.52

\begin{tabular}{llll}
\hline Site & $\begin{array}{l}\text { ACTH } \\
(\mathbf{p g} / \mathbf{m L})\end{array}$ & Cortisol (nmol/L) & Prolactin (mU/L) \\
\hline R/ Inferior Petrosal sinus & 91.91 & 476.5 & 610.8 \\
L/ inferior petrosal sinus & 86.6 & 560.1 & 471.2 \\
R/ Internal Jugular Vein & 68.6 & 539 & 489.2 \\
L/ Internal Jugular Vein & 38.53 & 512.8 & 320.8 \\
Femoral vein & 33.57 & 493.9 & 326.9 \\
\hline
\end{tabular}

1. What is the Endocrinological diagnosis of this patient?

ACTH dependent Cushing syndrome secondary to pituitary adenoma is the most possible diagnosis of this patient with the presentation and investigations.

\section{What is the cause for bilateral hip pain?}

$\mathrm{X}$ - ray AP view of bilateral hips shows presence of crescent sign and MRI findings are suggestive of bilateral avascular necrosis. Avascular necrosis of the hips are commonly caused by trauma or micro trauma ${ }^{(1)}$. Exogenous steroids are the commonest cause for non-traumatic avascular necrosis of the hip. However, even though uncommon, untreated endogenous hypercortisolism is also known to cause avascular necrosis of the hip as in this patient. Avascular necrosis occurs either due to intraluminal obstruction of the blood vessels by microthrombi, emboli or extraluminal obstruction due to marrow oedema $^{(1)(2)}$. Femoral head is more susceptible to avascular necrosis due to the limited blood supply through the artery of ligamentum teres ${ }^{(3)}$. The exact mechanism of in hypercortisolism is not clear. It is hypothesized that decreased bone remodeling that occurs in cortisol excess leads to impaired bone formation increasing the risk of necrosis of bone.

\section{How would you manage this patient?}

She was immediately referred for transsphenoidal surgery for resection of pituitary adenoma. Bilateral hip replacement was scheduled to be done after achieving eucortisolism.

Hip pain should not be neglected in patients with features of hypercortisolism. MRI of hip joints are the preferred diagnostic method as $\mathrm{X}$-ray is often normal. Sensitivity of X-ray in detecting early stages of avascular necrosis is as low as $41 \% 0^{(4)}$.

\section{References}

1. Lafforgue P. Pathophysiology and natural history of avascular necrosis of bone. Joint Bone Spine. $2006 \quad$ Oct;73(5):500-7. doi: 10.1016/j.jbspin.2006.01.025. Epub 2006 Aug 8. PMID: 16931094.

2. Glueck CJ, Freiberg R, Tracy T, Stroop D, Wang P. Thrombophilia and hypofibrinolysis: pathophysiologies of osteonecrosis. Clin Orthop Relat Res. 1997

Jan;(334):43-56. PMID: 9005895.

3. Koch CA, Tsigos C, Patronas NJ, Papanicolaou DA. Cushing's disease presenting with avascular necrosis of the hip: an orthopedic emergency. J Clin Endocrinol Metab. 1999 Sep;84(9):3010-2. doi: 10.1210/jcem.84.9.5992. PMID: 10487656. 
4. Stoica Z, Dumitrescu D, Popescu M, Gheonea I, Gabor M, Bogdan N. Imaging of avascular necrosis of femoral head: familiar methods and newer trends. Curr Health Sci J. 2009 Jan;35(1):238. Epub 2009 Mar 21. PMID: 24778812; PMCID: PMC3945237. 